\title{
Experimetal Studies
}

\section{Identification of Regulated Genes in Rat Heart after Myocardial Infarction by Means of Differential mRNA Display}

\author{
Yi Zhun Zhu, ${ }^{1,2}$ MD, Yi-Chun Zhu, ${ }^{1}$ MD, Monika Stoll, ${ }^{1} \mathrm{Ph}$ D, \\ and Thomas UNGER, ${ }^{1} \mathrm{MD}$,
}

\section{SUMMARY}

In order to testify the hypothesis that unknown mechanisms are involved in the process of cardiac remodeling after myocardial infarction (MI), we employed differential display reverse transcription-polymerase chain reaction (DDRT-PCR) as our primary inspection tool. An animal model of MI was established by ligation of the left anterior descending coronary artery (LAD) in rat. Fifty upregulated candidate cDNA fragments were obtained in the right ventricle $(\mathrm{RV})$ of the heart six weeks after MI. Eight cDNA fragments isolated from DD denaturing gel were extracted and reamplified, cloned into pCR II vector and sequenced. A Genbank search of these clones showed that three of them have a high homology with known genes not previously associated with cardiac remodeling, i.e., mouse interleukin-4 receptor gene, rat ferritin mRNA, and $\mathrm{T}$-cell receptor beta chain $\mathrm{V}$ beta 5 . The remaining clones have no similarity to known sequences. These data suggest that certain genes which were not previously being associated with cardiac hypertrophy are turned on during the process of cardiac remodeling after MI. (Jpn Heart J 2000; 41: 59-66)

Key words: Gene expression, Myocardial infarction, Differential display, Cloning, Polymerase chain reaction

$\mathrm{M}$ YOCARDIAL infarction (MI) induces remodeling of the viable myocardium and results in cardiac hypertrophy which is an independent cardiovascular risk factor. Numerous studies have been performed to investigate the mechanisms of cardiac hypertrophy, amongst which, activation of the renin angiotensin system (RAS) and endothelin have been demonstrated to be important

From the ${ }^{1}$ Department of Pharmacology, Christian-Albrechts University of Kiel, 24105 Kiel, Germany and ${ }^{2}$ Department of Pharmacology, Faculty of Medicine, National University of Singapore, Singapore.

Address for correspondence: Y.Z. Zhu, MD, Department of Pharmacology, Faculty of Medicine, National University of Singapore, 10 Kent Ridge Crescent, Singapore.

Received for publication September 27, 1999.

Revised and accepted December 2, 1999. 
pathways between MI and the following cardiac hypertrophy. ${ }^{1,2)}$ On the other hand, many of the mammalian genes have not been cloned. A hypothesis arose that some unknown mechanisms which may be explained by the expression of unknown genes could be involved in the process of cardiac remodeling after MI. It has been reported that brief periods of ischemia are strong inducers of gene expression. $^{3-6)}$ However, a link between increased transcription of a mRNA species and adaptational changes has not been established. ${ }^{7)}$ In the present study, we employed differential display reverse transcription-polymerase chain reaction (DDRT-PCR) to show the gene expression pattern in rat heart six weeks after MI.

\section{Materials and Methods}

Animal model of myocardial infarction: Male Wistar rats weighing between 250 and $300 \mathrm{~g}$ were used as the experimental animals. MI was induced by left anterior descending coronary artery (LAD) ligation. ${ }^{8}$ Six weeks after MI, the rats were decapitated, the hearts quickly dissected out, and the right ventricles isolated, weighed and immersed in liquid nitrogen and stored at $-80^{\circ} \mathrm{C}$.

RNA isolation and Northern blot analysis: Right ventricle was homogenized in $10 \mathrm{~m} l$ GIT buffer and total RNA was extracted according to the guanidinium thiocyanate-phenol-chloroform method. ${ }^{9)}$ For Northern blot analysis, $30 \mu \mathrm{g}$ total RNA from the right ventricles of sham-operated and MI-affected rats was transferred to a nylon membrane (Hybond-N hybridization transfer membrane, Amersham) after agarose gel electrophoresis. The membrane was hybridized with cDNA probes, which were digested from pCR Vector and labeled with random primers using a labeling kit (Promega) and $50 \mu \mathrm{Ci}$ of $\left[{ }^{32} \mathrm{P}\right] \mathrm{dCTP}$.

Differential display: Total RNA from 8 MI-affected and 12 sham-operated rats was pooled into two groups: MI- and sham groups, respectively. The pooled RNA was reverse transcribed with the anchored primers $\mathrm{d}(\mathrm{T}) 11 \mathrm{CT}$ using a reverse transcriptase-PCR kit (Gibco). An anchored primer and one of the short 10-mer arbitrary primers from 26 upstream primers ${ }^{10)}$ were used for the PCR amplification reaction in the presence of $\left[{ }^{32} \mathrm{P}\right] \mathrm{dCTP}$ for $5 \mathrm{~min}$ at $94^{\circ} \mathrm{C}$ for 1 cycle; 30 seconds for each at $94^{\circ} \mathrm{C}, 1$ minute at $40^{\circ} \mathrm{C}$ and 30 seconds at $72^{\circ} \mathrm{C}$ for 40 cycles; and $5 \mathrm{~min}$ at $72^{\circ} \mathrm{C}$ for the last cycle. Three $\mu \mathrm{l}$ of each sample with $2 \mu \mathrm{l}$ of stop solution were denatured for $5 \mathrm{~min}$ at $80^{\circ} \mathrm{C}$ and loaded on a $6 \%$ native polyacrylamide sequencing gel. The electrophoresis was performed using a current of 2,000 V and 75mA, for 2-3 hours. The dried gel was exposed to Kodak $\mathrm{X}$-ray film for 2 days.

Cloning and sequencing analysis of cDNA: Eight reamplified cDNAs isolated from differential display gel were cloned into the pCR II vector using a TA cloning kit (Invitrogen, San Diego, USA). The cloned vector was used to 
transform TA One Shot competent cells. For plasmid preparation, white colonies were selected from LB agar plates containing $50 \mu \mathrm{g} / \mathrm{m} l$ Ampicillin and $40 \mu \mathrm{g} / \mathrm{m} l$ $\mathrm{X}$-gal (Promega). DNA sequence analysis of cDNA was performed according to the manufacturer's instructions using an fmole-sequencing kit (Promega). Bands of interest with differences in the patterns of sham-operated and MI-affected groups on the polyacrylamide gel and 3MM Whatman paper were cut, rehydrated in $100 \mu l \mathrm{H}_{2} \mathrm{O}$ and eluted by boiling for 15 minutes. After a brief spin, the supernatant was precipitated with $10 \mu l 3 \mathrm{M}$ sodium acetate and $300 \mu l 96 \%$ ethanol and redissolved in $10 \mu l \mathrm{H}_{2} \mathrm{O}$ and reamplified by PCR with the same primers with which DDTR-PCR was performed.

\section{Results}

The cDNA fragments of the pooled right ventricular mRNA of the

Figure 1. $6 \%$ polyacrylamide gel of DDRT-PCR from rat right ventricle six weeks after MI. The fragments were labeled with ${ }^{32} \mathrm{P}-\mathrm{dCTP}$ and exposed with Kodak X-ray film. In the MI group, the fragment (arrow indicated) was significantly up-regulated compared to the sham group. S: sham operated rats; MI: myocardial infarcted rats. 


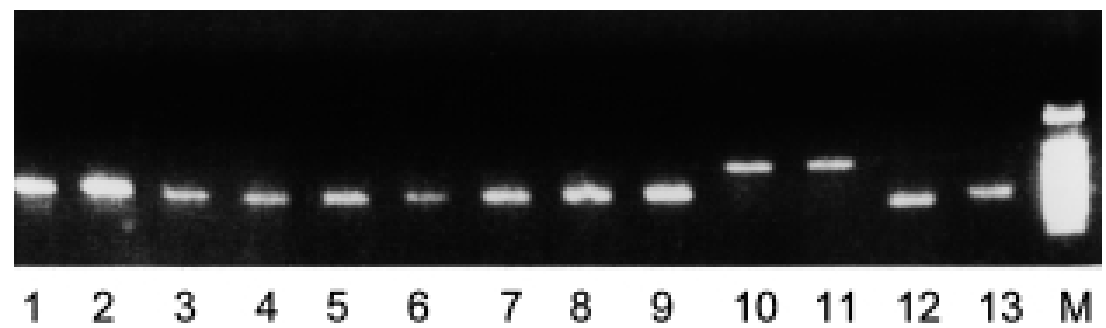

Figure 2. $1 \%$ agarose gel from reamplified bands using primer $\mathrm{d}(\mathrm{T}) 11 \mathrm{CT}$ and upstream primer at high stringency conditions. M: DNA molecular marker. Line 1-13: reamplified PCR products from differentially expressed fragments extracted from $6 \%$ polyacrylamide gel.

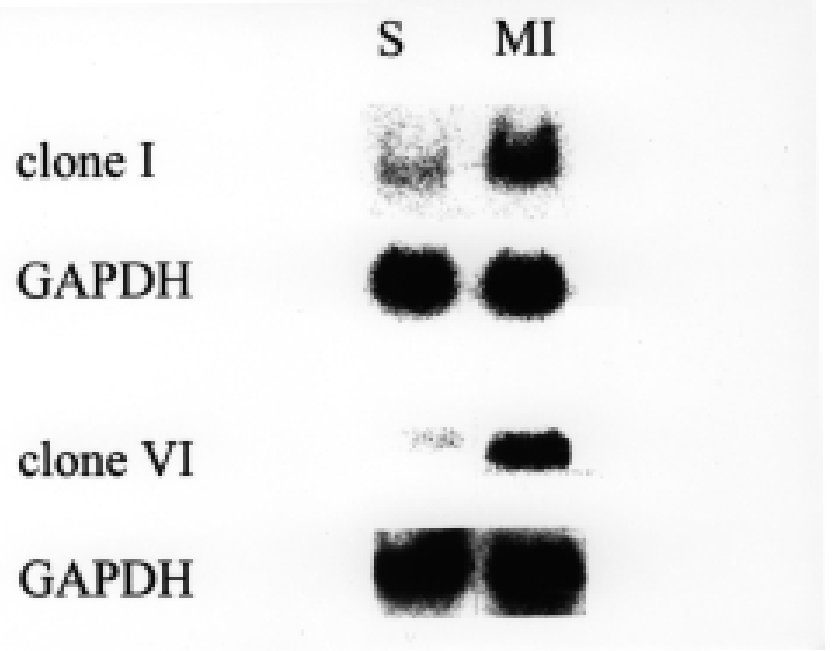

Figure 3. Northern hybridization of the isolated genes (clone I and clone VI) from differential display. S: sham operation; MI: myocardial infarction.

MI-affected and sham-operated groups were identified by DDRT-PCR (Figure 1). Eight cDNA bands (designated as clone 1-VIII) which represent up-regulated genes in the right ventricle were excised from the polyacrylamide gel, reamplified (Figure 2), cloned and sequenced. Northern hybridization demonstrated that clone I and clone VI showed positive signals (Figure 3) with mRNA from right ventricle of the MI-affected rat but not the sham-operated rat. The other 6 clones showed no positive signals with mRNA from either the MI-affected or sham-operated rats. A Genbank search showed that five of the clones correspond to unknown genes, whereas the other three represent known genes not previously associated with MI. The latter group includes the mouse interleukin-4 receptor gene ( $89 \%$ homology), rat ferritin mRNA (93\% homology) and T-cell receptor beta chain $\mathrm{V}$ with $80 \%$ homology (Table). 
Table. Identification of Isolated CDNA Clones

\begin{tabular}{lll}
\hline clone I & mouse interleukin-4 receptor & $89 \%$ identity \\
clone II & rat ferritin mRNA & $93 \%$ identity \\
clone III & T-cell receptor beta chain V & $80 \%$ identity \\
clone IV-VIII & unknown & \\
\hline
\end{tabular}

\section{DisCUSSION}

Our study demonstrates that certain genes with new sequences or with known sequences which were not previously associated with cardiac hypertrophy were significantly up-regulated in hypertrophied right ventricle. The up-regulated cardiac genes may play a role in the mechanisms of cardiac hypertrophy following MI. Previous studies have demonstrated some well recognized mechanisms of cardiac hypertrophy such as RAS activation. RAS elements such as angiotensin converting enzyme (ACE), ${ }^{11,12}$ and angiotensin (Ang) II receptor subtypes AT1 and AT2 ${ }^{13,14)}$ have been reported to be up-regulated in rat heart after MI. Blockade of RAS with either ACE inhibitors or Ang II AT1 receptor antagonists were able to prevent cardiac hypertrophy following MI. ${ }^{15)}$ However, our studies showed for the first time that certain unknown genes as well as some known genes which were not previously associated with myocardial hypertrophy were associated with right ventricular (RV) hypertrophy after MI. These data suggest that cardiac hypertrophy is a multi-mechanism pathological process in which many unrecognized mechanisms may be involved.

Three of the up-regulated cardiac genes identified in the present study have high homology with known genes not preciously associated with cardiac hypertrophy, i.e., mouse interleukin-4 receptor gene ( $89 \%$ homology), rat ferritin mRNA (93\% homology) and T-cell receptor beta chain V (80\% homology). Interleukin-4 (IL-4) has been shown to play a crucial role in the pathogenesis of allergic inflammation. ${ }^{16)}$ There is increasing evidence that inflammation is associated with acute coronary syndromes such as myocardial infarction. ${ }^{17)}$ Ferritin is an iron storage protein that is regulated at the transcriptional levels, resulting in a complex mixture of tissue- and condition-specific isoforms. Like heart ferritin, lung ferritin exhibited a low iron content that did not increase extensively in response to iron challenge, which contrasts with ferritins isolated from liver or spleen. ${ }^{18)}$ In liver and spleen, ferritin synthesis is under translational control by iron, and both tissues also respond to inflammation by the shifting of ferritin mRNA to the polyribosomes. ${ }^{19)}$ However, whether rat ferritin mRNA is related to MI remains to be elicited. It is reported that specific immunotherapy with synthetic $\mathrm{T}$-cell receptor $\mathrm{V}$ alpha or $\mathrm{V}$ beta peptides can prevent $\mathrm{T}$-cell- 
mediated myocardial damage in patients with viral myocarditis. ${ }^{20)}$ There is no direct evidence indicating the involvement of $\mathrm{T}$-cell receptor beta chain $\mathrm{V}$ in cardiac remodeling phase. Further studies such as transfer and expression of the up-regualted genes are necessary to achieve this goal. DDRT-PCR was first described by Liang and Pardee ${ }^{21)}$ and improved by Bauer, et al. ${ }^{10)}$ This method has the advantage of making about 20,000 mRNAs that an interested population of homogeneous cells is assumed to express, ${ }^{10)}$ such that it can be visually compared on the sequencing gel with that from control tissue. With this method, Knoll, et $a l^{7)}$ and Deindl and Schaper ${ }^{22)}$ identified differentially expressed clones with new sequences following a brief coronary artery occlusion in the ischemic region of porcine heart. We first identified up-regulated genes with new sequences or with known sequences which were not previously associated with cardiac hypertrophy in rat heart six weeks following MI. For the discovery of previous unidentified genes, DDRT-PCR is superior to other differential strategies of molecular cloning. However, this method has the disadvantage of generating false positive clones. In our pre-experiments, we could even identify differential clones between two samples from the same experimental group. When the number of samples was expanded, we observed that the appearance of these differential clones within the same group was random. When we pooled the samples which were from the same group into two groups and compared the two pooled samples by DDRT-PCR, the random differential clones were minimized by about $90 \%$ (Zhu, et al. unpublished). In the present study, we modified the method by including relatively large samples in each group, i.e., 8 in the MI group and 12 in the sham group, to perform DDRT-PCR. The RNA was pooled according to the two groups. With DDRT-PCR of pooled MI- and sham groups, we selected only bands present on the lane of pooled MI group and absent on the pooled sham group. Therefore, the differential clones we selected were fairly specific. In the present study, two of the eight showed positive signals with mRNA from right ventricle of the MI rat but not the sham rat. It confirmed the mRNA origin of heart of the differential clones. Although the remaining six may represent cardiac mRNAs which are not detectable by Northern hybridization, their value are limited without further investigation. On the other hand, because of the strict standard set in the present study to select the differential clones, some differential clones might be ignored. The right ventricle of the MI group showed significant hypertrophy in comparison with the sham group six weeks after operation. LVEDP increased significantly in the MI group in the present study. RV hypertrophy was induced by pulmonary hypertension followed by increased LVEDP and decreased LV out put. The data of DDRT-PCR suggest that up-regulated genes we identified in the right ventricle have a significant association with RV hypertrophy. We are currently performing experiments to 
reveal the mechanisms of the involvement of these identified genes in the process of cardiac remodeling which results in cardiac hypertrophy.

In conclusion, certain genes which were not previously being associated with cardiac hypertrophy are turned on during the process of cardiac remodeling after MI.

\section{REFERENCES}

1. Zhu YZ, Zhu YC, Stoll M, et al. Identification of differentially regulated genes in the rat heart after myocardial infarction. J Hypertension 1996; 14(Suppl 1): S84.

2. Zhu YC, Zhu YZ, Gohlke P, et al. Effects of converting enzyme inhibition and angiotensin II AT1 receptor antagonism on cardiac parameters in left ventricular hypertrophy. Am J Cardiol 1997; 80 (3A): 110A-7A.

3. Andres J, Sharma HS, Knoll R, et al. Expression of heat shock proteins in the normal and stunned porcine myocardium. Cardiovasc Res 1993; 27: 1421-9.

4. Brand T, Sharma HS, Fleischmann KE, et al. Proto-oncogene expression in porcine myocardium subjected to ischemia and reperfusion. Circ Res 1992; 71: 1351-60.

5. Frass O, Sharma HS, Knoll R, et al. Enhanced gene expression of calcium regulatory proteins in stunned porcine myocardium. Cardiovasc Res 1993; 27: 2037-43.

6. Knoll R, Arras M, Zimmermann R, et al. Changes in gene expression following short coronary occlusions studied in porcine hearts with run-on assays. Cardiovasc Res 1994; 28: 1062-9.

7. Knoll R, Zimmermann R, Arras M, et al. Characterization of differentially expressed genes following brief cardiac ischemia. Biochem Biophys Res Commun 1996; 221: 402-7.

8. Johns TNP and Olson BJ. Experimental myocardial infarction: a method of coronary occlusion in small animals. Ann Surg 1954; 140: 675-82.

9. Chomczynski P, Sacchi N. Single-step method of RNA isolation by acid guanidinium thiocyanatephenol-chloroform extraction. Anal Biochem 1987; 162: 156-9.

10. Bauer D, Mueller H, Reich J, et al. Identification of differential expressed mRNA species by an improved display technique (DDRT-PCR). Nucleic Acids Res 1994; 21: 4272-80.

11. Sun Y, Cleutjens JP, Diaz-Arias AA, et al. Cardiac angiotensin converting enzyme and myocardial fibrosis in the rat. Cardiovasc Res 1994; 28: 1423-32.

12. Falkenhahn M, Franke F, Bohle RM, et al. Cellular distribution of angiotensin-converting enzyme after myocardial infarction. Hypertension 1995; 25: 219-26.

13. Y.C. Zhu, Y.Z. Zhu, J. Li, et al. Early changes of cardiac gene transcription levels of angiotensin II receptors after myocardial infarction: effects of Ramipril treatment. Acta Pharmacol Sinica 1999; 20: 481-5.

14. Nio Y, Matsubara H, Murasawa S, et al. Regulation of gene transcription of Angiotensin II receptor subtypes in myocardial infarction. J Clin Invest 1995; 95: 46-54.

15. Stauss HM, Zhu YC, Redlich T, et al. Angiotensin-converting enzyme inhibition in infarct-induced heart failure in rats: bradykinin versus angiotensin II. J Cardiovas Risk 1994; 1: 255-62.

16. Collins H, Flesch IE, Emoto M, et al. Interleukin-4 production in response to infection with intracellular bacteria. Adv Exp Med Biol 1998; 452: 75-83.

17. Whicher J, Biasucci L, Rifai N. Inflammation, the acute phase response and atherosclerosis. Clin Chem Lab Med 1999; 37: 495-503.

18. Ryan TP, Krzesicki RF, Blakeman DP, et al. Pulmonary ferritin: differential effects of hyperoxic lung injury on subunit mRNA levels. Free Radic Biol Med 1997; 22: 901-8.

19. Campbell CH, Solgonick RM, Linder MC. Translational regulation of ferritin synthesis in rat spleen: effects of iron and inflammation. Biochem Biophys Res Commun 1989; 160: 453-9. 
20. Seko Y, Yagita H, Okumura K, et al. T-cell receptor V beta gene expression in infiltrating cells in murine hearts with acute myocarditis caused by coxsackievirus B3. Circulation 1994; 89: 2170-5.

21. Liang P \& Pardee AB. Differential display of eukaryotic messenger RNA by means of the polymerase chain reaction. Science 1992; 257: 967-71.

22. Deindl E, Schaper W. Gene expression after short periods of coronary occlusion. Mol Cell Biochem 1998; 186: 43-51. 